\title{
COMPARISON BETWEEN CLASSIC AND FUZZY LOGIC METHOD ON CORROSION RATE OF ZINC METAL IN DILUTED SULPHURIC ACID AFTER NITRIDATION PROCESS
}

\author{
Sahat Simbolon \\ Center for Accelerator Material Process Technology \\ National Nuclear Energy Agency (BATAN) \\ Jl. Babarsari, Kotak Pos 6101 Ykbb
}

\begin{abstract}
COMPARISON BETWEEN CLASSIC AND FUZZY LOGIC METHOD ON CORROSION RATE OF ZINC METAL IN DILUTED SULPHURIC ACID AFTER NITRIDATION PROCESS. Nitridation of zinc metal in DC nitridation machine by varying temperature from $150^{\circ} \mathrm{C}$ to $300^{\circ} \mathrm{C}$ and time of nitridation from 15 to 75 minutes were carried out. Nitrided zinc metal were corroded in diluted sulfuric acid solution in room temperature. The relationship between corrosion rate of zinc metal with temperature and time of nitridation were described in classic method. The results found were not satisfied because it contained ambiguous, uncertainty and imprecision data. The relationship of two inputs and one output were also described by using Fuzzy Logic. The performance of Fuzzy Logic has been carried out through triangular, $\mathrm{S}$ and $\mathrm{Z}$ shape membership function for two inputs temperature and time respectively, and one output corrosion rate or $\mathrm{I}_{\text {Corr }}$. Meanwhile two trapezoidals and one triangular were used for output corrosion rate. Nine rules were used to perform defuzzyfication, and it was also described three dimensions relationship between temperature, time of nitridation and corrosion rate. The results found that maximum corrosion rates were found in the three parts, but the lowest corrosion rate was found at the middle temperature and the lowest time of nitridation as shown in the surface viewer.
\end{abstract}

Key Words : Zinc metal, Nitridation, Corrosion Rate, Classic Method, Fuzzy Logic.

\section{INTRODUCTION}

Zinc is an important element in industrial world, it is used range from metal products to rubber, paint and agricultural industries. Zinc is produced by converting of the earth's crust or ores mineral into zinc metal or its alloys. External energy is applied in the conversion of ores mineral to zinc metals or its alloys. Thermodynamically zinc metal has a tendency to go back to a lower energy by reacting with others elements in the environment. This process is very slow and is called a corrosion [1].

The corrosion of zinc in pure water is slow but in water its corrosion will be higher because of impurities present in the water. On the other hand, the corrosion rate of zinc is faster in acid and strong alkaline solutions than in water solution. Even in dilute concentration of acid, zinc will be corroded rapidly and alkaline solution is much less corrosive than corresponding concentration of acid [1].

Corrosion is the destructive result of electrochemical reaction involves two half-cell electrochemical reactions. They are a reduction electrochemical reaction at the cathode and an oxidation electrochemical reaction at the anode. There are three common cathodic reactions, oxygen reduction (fast), 
hydrogen evolution from neutral water (slow), and hydrogen evolution from acid (fast).

These half cell electrochemical reactions of zinc corroding in water with a near neutral condition can be represented as:

$$
\begin{array}{cc}
2 \mathrm{Zn} \rightarrow 2 \mathrm{Zn}^{2+}+4 \mathrm{e}^{-} & \text {Anodic reaction } \\
\mathrm{O}_{2}+2 \mathrm{H}_{2} \mathrm{O}+4 \mathrm{e}^{-} \rightarrow 4 \mathrm{OH}^{-} & \text {Cathodic reaction }
\end{array}
$$

For different metals exposed to various environments, there will be a different anodic and cathodic electrochemical reactions and there will be different result.

There are some methods which could be done to protect zinc metal from corroding, one of them is nuclear technique by using plasma thermomechanical processes in this case is ion nitriding technology to modify zinc metal surface. Ions nitriding are produced in vacuum chamber's wall as an anode and the zinc metal being processed which has a high voltage. Ions nitriding in the vacuum chamber become more reactive or ion nitriding has high energy, so ion nitriding will react with the target zinc metal. There are two kinds of reaction between ion nitriding and zinc metal, they are diffusion and thermo-chemical reaction which produce a thin layer. Diffusion mechanism will be able to penetrate the surface of the zinc metal. Those reactions yield in hardening surface of zinc metal.

Basically, the nitriding zinc metals aims are to harden the surface of zinc metal, to increase wear resistance, to improve fatigue life and to improve corrosion resistance. Reaction between ion nitriding and zinc on the surface is not easy to be described, but reaction between iron and ion nitriding can be described as an adsorption of atomic nitrogen and chemical reaction forming FeN. The end result of the bombarding zinc metal with ion nitriding is film layer on the surface. The reaction mechanism of nitriding has generally been known, but the specific reactions that occur in different steels and with different nitriding media have not been known yet. Chemical reaction between metal and ion nitriding depends on the concentration of nitrogen in the chamber. Chemical reaction between iron and about $6 \%$ nitrogen will produce $\mathrm{Fe}_{4} \mathrm{~N}$, at nitrogen concentration greater than $8 \%$ the end result is $\mathrm{Fe}_{3} \mathrm{~N}[2,3]$.

If nitriding zinc metal had improved corrosion resistance it would be better to introduce nitrogen in varying temperature and time of nitridation. The relationships between temperature and time of nitridation versus corrosion rate $\left(\mathrm{I}_{\text {Corr }}\right)$ respectively will show the weakness of classic method. In addition, it was also useful to apply Fuzzy Logic since the experiments with anode and cathode plasma nitriding in a glow discharge and measurements of corrosion rate have lot of imprecision and uncertainty. Fuzzy Logic method was used to describe the relationship between two inputs, temperature and time of nitriding and one output which is called corrosion rate $\left(\mathrm{I}_{\text {Corr }}\right)$ in sulfuric acid solution. In this system a fuzzyfication interface transforms the input in degrees of match with linguistic values. 
Then a decision-making unit performs the inference operations on the rules base. Finally, a defuzzyfication interface transforms the fuzzy result of the inference process in a crisp output [4].

\section{EXPERIMENT}

The materials are used for this experiment are pure nitrogen gas, zinc metal, abrasive paper 400 mesh, 600 mesh, autosol paste, alcohol $70 \%$, sulfuric acid (Merck).

Several instruments that are used for nitridate i.e DC Nitridation Machine (PPNY $150 \mathrm{k} \mathrm{eV} / 2 \mathrm{~mA}$ ), Polishing machine, Ultrasonic Cleaner. Potensiostat/Galvanostat PGS 201 T.(Tacussell).

This experiment is devided in two parts, first was about nitriding process and second about the Corrosion of the metal.

\section{Nitriding process}

The preparation and procedure for this experiment have been described in details elsewhere [6]. It consists of plasma power, external heater, cooling unit, evacuation unit, vacuum chamber, nitrogen gas supplier unit. Each specimen was cut $1.4 \mathrm{~cm}$ in diameter, polished on abrasive paper and washed. Washing with ultrasonic cleaner was done with alcohol $70 \%$ for 30 minutes, polished with autosol paste and dried at room temperature. The specimens were laid on the anode position. The pressure on the vacuum chamber is $310^{-2}$ Torr, current $40 \mathrm{~mA}$, voltage $2 \mathrm{kV}$ and the distance anode and cathode $2.5 \mathrm{~cm}$. The specimens were ion-nitridied were varied from 15 minutes until 75 minutes and the specimens were heated from $150^{\circ} \mathrm{C}$ until $300^{\circ} \mathrm{C}$. Ion nitriding was done in nitrogen gas admitted through valves after evacuation. High voltage was on after pressure of vacuum chamber was $10^{-4}$ Torr. High voltage was arranged between 1 and $2.5 \mathrm{kV}$. Nitrogen gas flowing was stopped when deposition time was enough, and high voltage was off. Target was taken out of the vacuum chamber. Each samples was kept in a plastic bag and each of them was labeled in temperature, time of of deposition, pressure of the chamber and high voltage.

\section{Corrosion of zinc metal}

Each sample was placed in working electrode, sample nitrided was faced on to the solution used. Other electrodes were put in their position respectively. Sulfuric acid solution was used to test the resistant of corrosion each sample nitrided, concentration of sulfuric acid was $0.001 \mathrm{M}$. All the measurements were connected to the potensiostat, the potential was varied from $-2000 \mathrm{mV}$ to $2000 \mathrm{mV}$ and the scanning rate was $20 \mathrm{mV} /$ second. The potensiostat showed the relationship between potential curve and log current intensity. By use the computer, it would be found the Tafel line which 
showed the $\mathrm{I}_{\mathrm{Corr}}$ and potential corrosion of each samples measured which were measured in room temperature.

\section{RESULTS AND DISCUSSION}

First of all, zinc metal samples were nitrided in the DC nitriding machine. Nitriding process had to be run in vacuum chamber and nitrogen gas was admitted in order to get nitride radical or nitrogen positive ion. Nitrogen positive ions were produced and would be deposited in the surface of the target, in this case the target was zinc metal. Interaction between nitrogen positive ion and zinc metal surface results physical and chemical properties such as the surface of zinc metal will be harder and corrosion rate of zinc metal will be reduced as it is happened for iron [6]. Corrosion rate of metal corresponding with surface of the metal, reaction between nitrogen positive ion and zinc metal surface is important to study. Since zinc metal has the fastest corrosion rate among all the metals, so zinc metal is good for studying nitridation.

Due to their application of ion nitriding equipment, temperature were varied from $150^{\circ} \mathrm{C}$ until $300^{\circ} \mathrm{C}$, meanwhile time for nitriding were varied from 15 minutes until 75 minutes. Furthermore, the experiment for electrochemical reaction in room temperature, sulfuric acid solutions used was $0.001 \mathrm{M}$. The experiment results can be seen in Table 1 .

Table 1. Relationship among Temperature and Time of Nitriding with Corrosion Rate $\mathrm{I}_{\text {Corr }}$ of Zinc Metal in Diluted Sulfuric Acid

\begin{tabular}{|c|c|c|}
\hline \multicolumn{2}{|c|}{ Nitridation Plasma } & Corrosion rate $\left(\mu \mathrm{A} / \mathrm{cm}^{2}\right)$ in \\
\hline Temperature $\left({ }^{\circ} \mathrm{C}\right)$ & Time (minutes) & $\mathrm{H}_{2} \mathrm{SO}_{4} 0.001 \mathrm{M}$ \\
\hline 150 & 15 & 1.08 \\
& 30 & 20.96 \\
& 45 & 8.26 \\
& 60 & 27.34 \\
& 75 & 34.06 \\
\hline 200 & 15 & 16.12 \\
& 30 & 23.04 \\
& 45 & 0.23 \\
& 60 & 10.37 \\
& 75 & 30.80 \\
\hline 250 & 15 & 32.21 \\
& 30 & 13.26 \\
& 45 & 34.63 \\
& 60 & 34.38 \\
& 75 & 18.86 \\
\hline 300 & 15 & 206.92 \\
& 30 & 213 \\
& 45 & 40.98 \\
& 60 & 3.54 \\
& 75 & 4.62 \\
\hline
\end{tabular}


Data from Table 1 above shows that two inputs, time and temperature of nitriding on zinc metal and one output, corrosion rate on zinc metal is in $0.001 \mathrm{M}$ sulfuric acid solution. Classic method was done by grouping the data above based on time of nitriding versus corrosion rate respectively, it would be found five graphs. Two of the graphs are almost the same from low until high temperature, both graphs show that short time of nitriding in high temperature will increase the corrosion rate. Both graphs are quite different than the three others are. The $\mathrm{I}_{\text {Corr }}$ of zinc metal was very high in high temperature experiment, even though time of nitriding was short zinc metal was headed for damage. But three others graphs show that the corrosion rate of zinc metal are almost the same to each other even though the experiment were done in low and high temperature and in short or long time of nitriding. It means nitriding of zinc metal for a longer time would not increase or reduce the corrosion rate of zinc metal, as shown Figure 1 below.

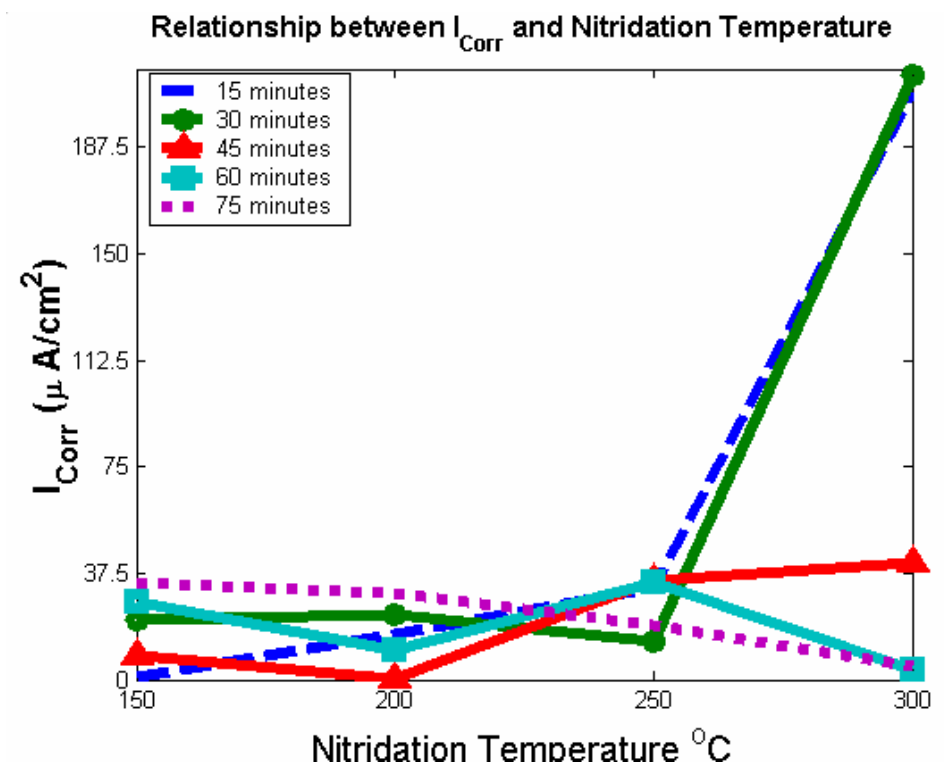

Figure 1. Relationship between nitridation temperature and $\mathrm{I}_{\text {Corr }}$ corrosion rate of zinc metal.

The result of the highest temperature of the first two of experiments were not consistent with the second three of the experiment. The uncertainty and imprecision results are depicted in Figure 1 above. This is a classic method which can depict inconsistency of the result found. Furthermore, it is supposed to have a big error in experiment because it contains ambiguous, uncertainty and imprecision data.

On the other hand, by grouping the data above based on nitridation time versus $\mathrm{I}_{\text {Corr }}$ of zinc metal, there would be found four graphs. Only one of them is far different from the others. When the experiment was done at $300^{\circ} \mathrm{C}$ 
and time of of nitriding for short time, the corrosion rate of zinc metal would be found very high, but others experiments show that corrosion rate is close to normal, since the normal corrosion rate of zinc metal when measured without nitriding and in water solution or without acid it was found $43.22\left(\mu \mathrm{A} / \mathrm{cm}^{2}\right)$. It shows that only small amount of nitrogen on the surface of zinc metal when the nitridation in short time or nitrogen atom is not attached to $\mathrm{Zn}$ metal properly when the temperature was $300^{\circ} \mathrm{C}$. As its consequence zinc metal was damage on that temperature, so its $\mathrm{I}_{\text {Corr }}$ was so high. On the other hand, when the nitridation time was rather longer caused more nitrogen were implanted on the surface of the metal, so the $\mathrm{I}_{\text {Corr }}$ of zinc metal was significantly low as shown in Figure 2 below.

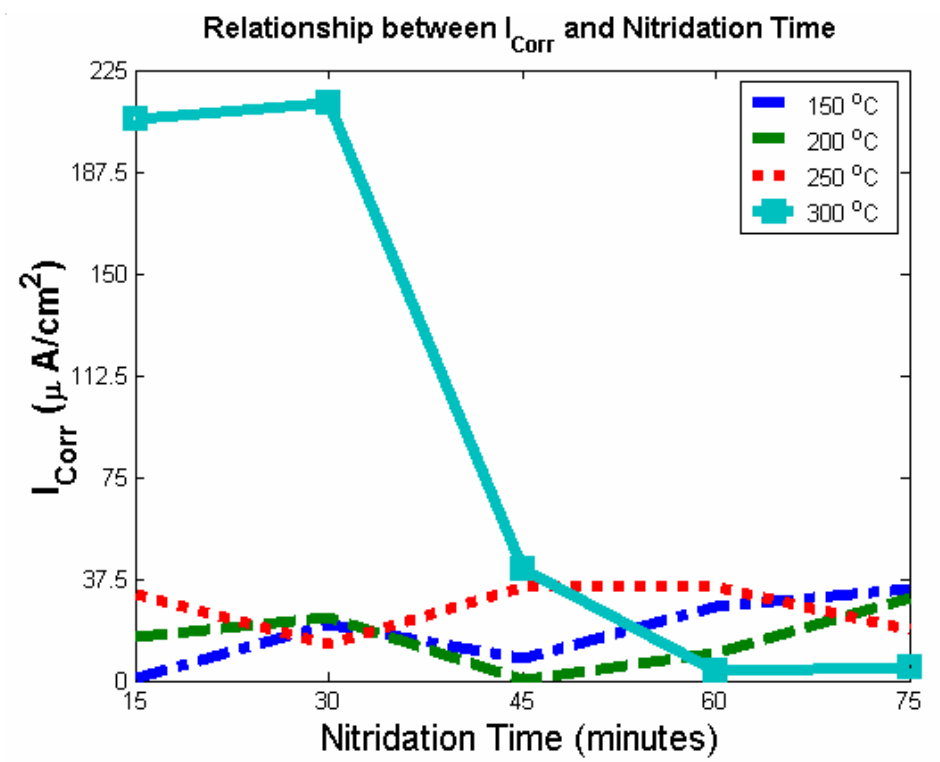

Figure 2. Relationship between time of of nitriding zinc metal and corrosion rate.

When the nitridation was held in low temperature or even rather high temperature for short or long nitridation time caused zinc metal corrosion rate rather low. In this case nitrogen is attached to $\mathrm{Zn}$ metal much more when the temperature was low until high especially when the nitridation time rather longer as shown on Figure 2 above. The relationship between corrosion rate ( $\left.\mathrm{I}_{\text {Corr }}\right)$ versus nitridation temperature and corrosion rate $\left(\mathrm{I}_{\text {Corr }}\right)$ versus nitridation time were not satisfied, the data found must have some ambiguous uncertainty and imprecision. As mention before, they could be brought out by an error in experiments. The uncertainty and imprecision data would lead to be incorrect in making further decision. So the relationships among the data found in Table 1 can not be described suitably as a simple relationship as in normal classic method. Classic method was failed to 
describe the relationship between corrosion rate and nitridation temperature and time respectively.

It needs a new method which can help to describe the relationship those ambiguous, uncertainty and imprecision data. Fuzzy Logic, however, is very useful for such data because it leads to a simple one which is more similar to human language. Fuzzy toolbox in Matlab was used to describe the relationship between two inputs and one output. Each input and output was divided into three membership functions, such as low, medium and high. Membership function may assume different shape like Gaussian, trapezoidal, S-shape etc. Each memberships has the advantages and disadvantages, such as Gaussian shape can achieve smoothness, but can not describe asymmetric membership functions, meanwhile trapezoidal shape is very simple one since it is built by three straight lines and S-shape can describe asymmetric membership functions [5].

Therefore the relationships among the data found in Table 1 were grouped into two parts, they are input which contains time and temperature of nitridation and one output which contains only one value it is $\mathrm{I}_{\text {Corr }}$. Each inputs and output would be treated using membership function plot which values between 0 and 1 . Furthermore, the data found were calculated by use Fuzzy Logic which has three steps ${ }^{(\mathbf{5 , 7 , 8 , 9 , 1 0})}$. For application of Fuzzy Logic for above experiments, we have to follow five steps, they are Fuzzy Inference System (FIS editor), Membership Function, Rule Editor, Rule Viewer and Surface Viewer. Since inputs of the experiments were done simultaneously, we have two inputs, they are temperature and time of nitriding, and one input, $\mathrm{I}_{\text {Corr }}$ of zinc metal as shown in Figure 3.

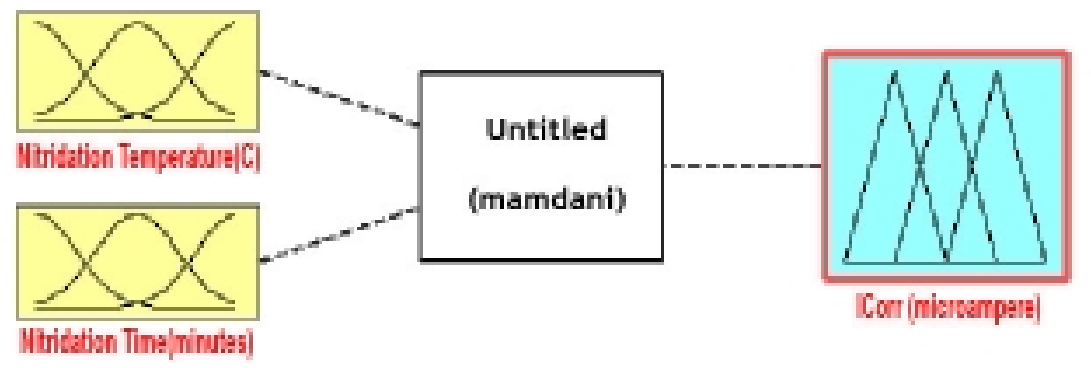

Figure 3. GUI of Fuzzy toolbox of input, nitridation temperature and nitridation time and output, $\mathrm{I}_{\text {Corr }}$.

A membership function is a curve that define how each point in the input space is mapped to a membership value (degree of membership) between 0 and 1 . Membership function of temperature from $150^{\circ} \mathrm{C}$ to $300^{\circ} \mathrm{C}$ is divided in to three membership function, they are low, medium and high. The value of membership function describes the degree of membership which values between 0 and 1 and the shape can be triangular or s-shape or bell shape. In this calculation low membership is Z-shape, medium membership 
function is Gaussian and high membership function is S-shape as shown Figure 4.

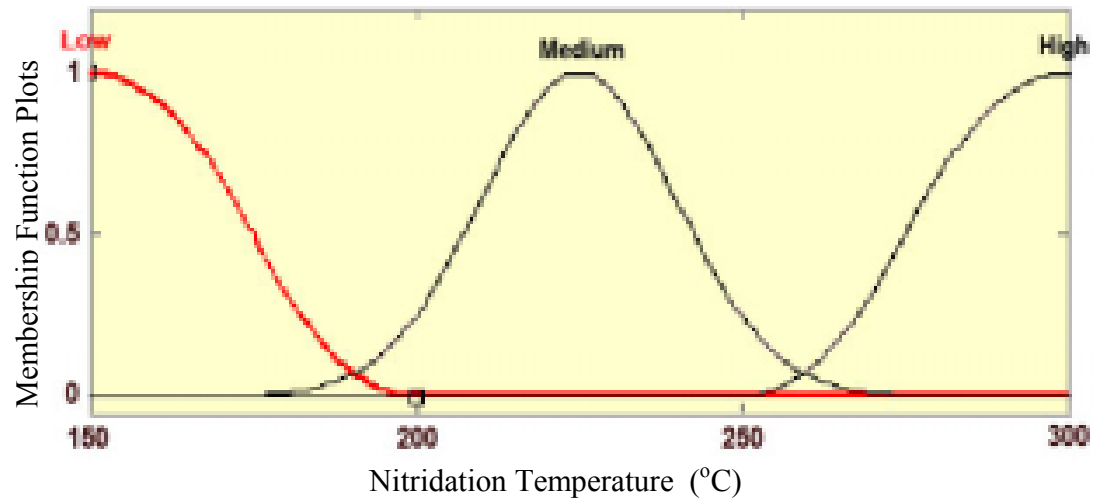

Figure 4. End result of choosing Z, Gaussian and S shape respectively for membership function plots.

Another membership function as an input which describes the time of nitriding, has also three categories, they are short, medium and long. The range of membership function is $150^{\circ} \mathrm{C}$ and $300^{\circ} \mathrm{C}$. The shape of membership function is the as the membership function of temperature as depicted in Figure 5.

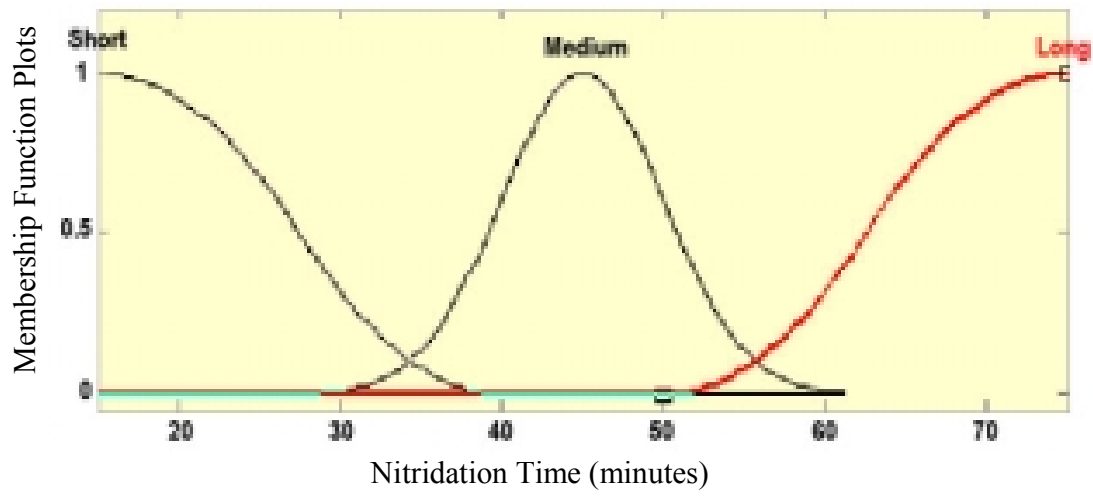

Figure 5. End result of choosing Z, Gaussian and S shape respectively.

The membership function of output is composed to trapezoidal for low and high categories respectively and one triangle for normal category as shown Figure 6 below. The range of time of nitriding is 15 minutes until 75 minutes. The current range of $\mathrm{I}_{\text {Corr }}$ is chosen from $0 \mu \mathrm{A}$ until $213 \mu \mathrm{A}$. The shape of membership function of temperature is as depicted in Figure 6 below. 


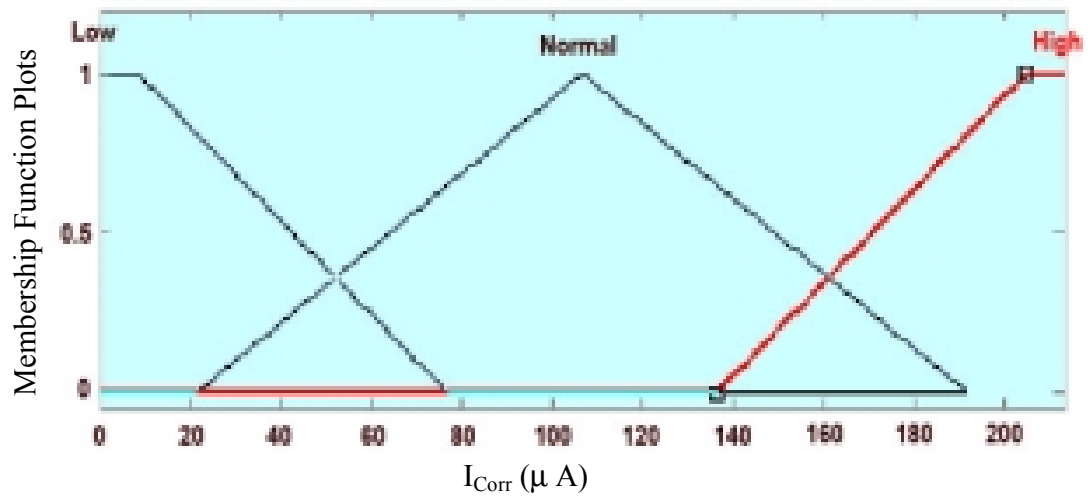

Figure 6. End result of choosing 2 trapezoidal and one triangular membership

The second step is to make the rules between input and output. The rules are very important because it would produce the end result based on the interaction the rules involved. Since there are two inputs and one output there would be found nine rules which can be created. All the rules created are written in the display as shown in the Figure 7 below.

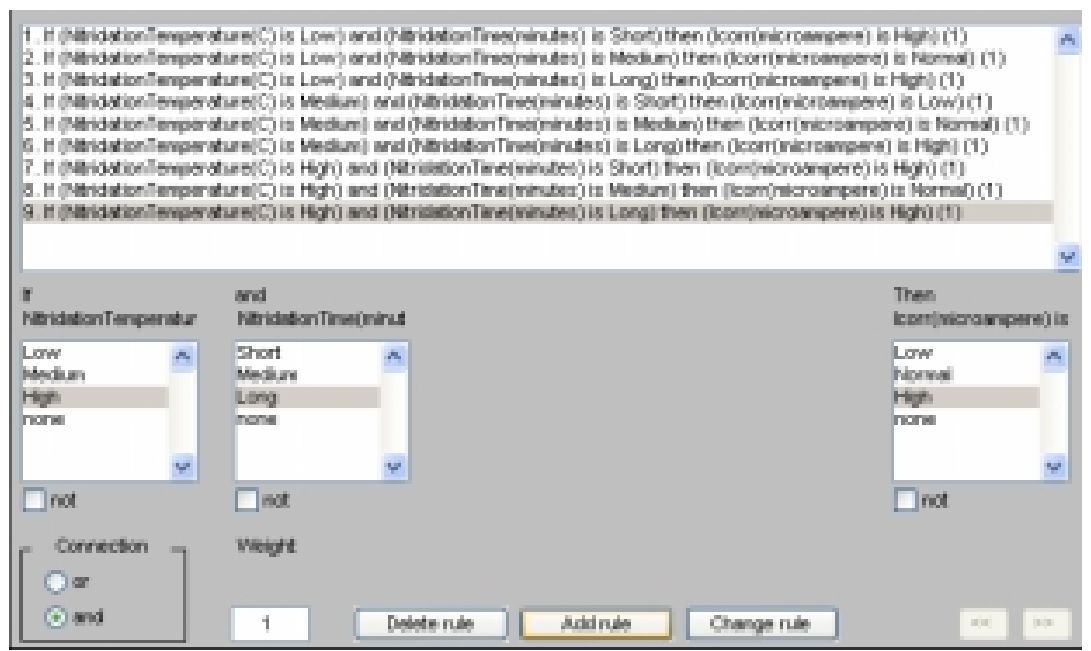

Figure 7. All the rules are written as a result of two inputs and one output.

The process of defuzzification is described as shown in Figure 8 below. Each rules written above is antecedent and consequent and it is depicted as shown below. The end result is found in the last box of $\mathrm{I}_{\text {Corr }}$. By changing the rules or the range, it will be found the other result. The number of rules can also be added or reduced in the ruler editor. 


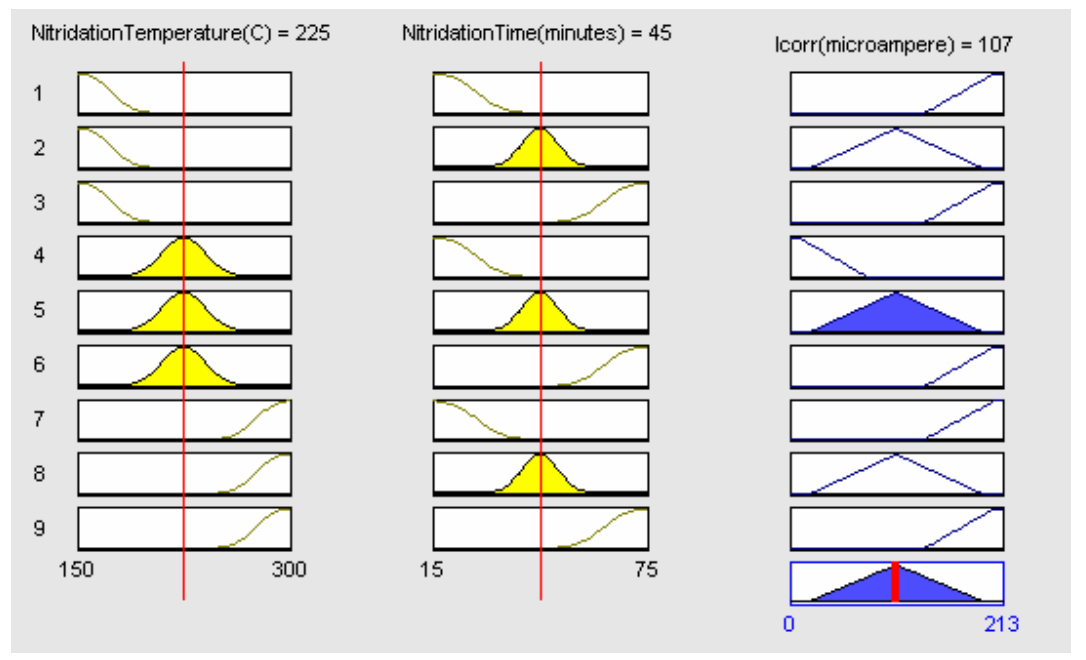

Figure 8. Rule viewer of 2 inputs and one output can be seen as a graphically of zinc metal $\mathrm{I}_{\text {Corr }}$ after nitriding.

The end result is found in the last box of $\mathrm{I}_{\mathrm{Corr}}$. By changing the rules or the range, it will be found the other result. The number of rules can also be added or reduced in the ruler editor.

Three dimensions relationship can be found by pressing surface viewer of Toolbox. The relationship is shown as depicted in Figure 9. If the rules were reduced the result would be different, so the result was strongly depend on the number of the rules put in the system.

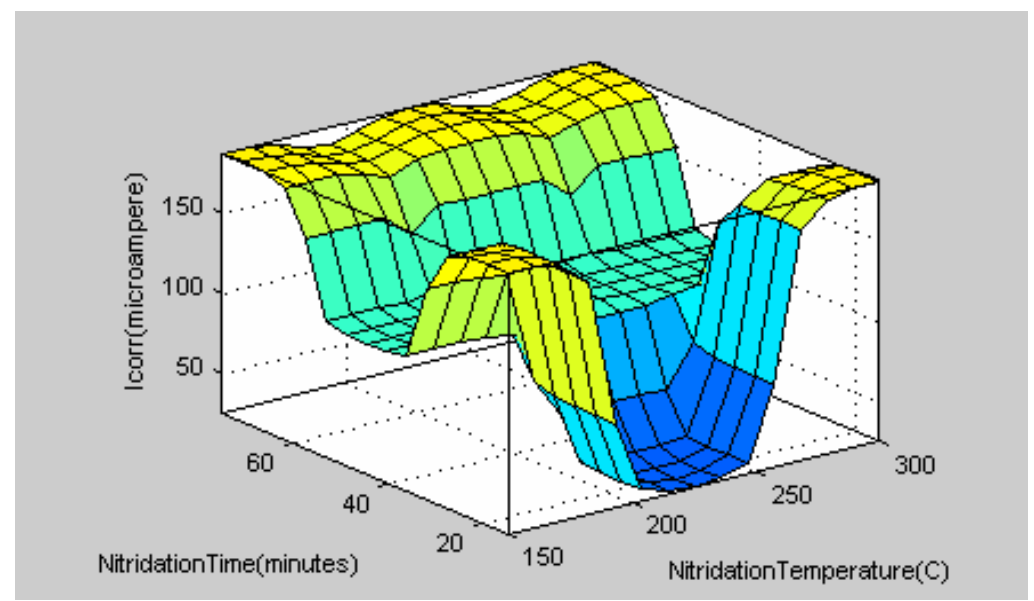

Figure 9. Three dimensions relationship among time of (time) and temperature of nitriding and $\mathrm{I}_{\text {Corr }}$ of zinc metal in $0.001 \mathrm{M}$ sulfuric acid. 
The relationship between of two inputs nitridation time and nitridation temperature and one input $\left(\mathrm{I}_{\text {Corr }}\right)$ can be seen on the surface viewer on the Figure 9 above. The highest corrosion rate was found when nitridation time was long and other the highest corrosion rate was also found when nitridation time was short and nitridation time were low or high. The lowest and the medium corrosion rate of nitrided $\mathrm{Zn}$ metal were also found in the Figure 9. So, it could be used as a mapping of nitriding time, nitriding temperature and $\mathrm{I}_{\text {Corr }}$ of zinc metal therefore it can be applied for using it as a preliminary guide.

Fuzzy Logic method is success to describe the relationship between corrosion rate and nitridation temperature and nitridation time in three dimensional from the data which are presented on Table 1. Meanwhile classic method does not bring out good relationship between corrosion rate of zinc metal and nitridation temperature and nitridation time respectively. One of the limitation of classic method does not tolerate with ambiguous, uncertainty and imprecision data, however, Fuzzy Logic is able to be practiced freely with ambiguous, uncertainty and imprecision data.

\section{CONCLUSION}

1. Classic method was not able to describe suitably the relationships among corrosion rate of zinc metal and nitridation temperature and nitridation time as shown in Figure1 and 2 respectively.

2. Classic method can only succeed in dealing with simple data and it is not suitable for ambiguous, uncertainty and imprecision data because it operates naturally.

3. Fuzzy Logic was able to describe the relationship of two inputs nitridation temperature and nitridation time and one output corrosion rate of zinc metal in three dimensions.

4. Fuzzy Logic method in the surface viewer of nitrided zinc metal showed where the location should be followed or avoided for the highest or for the lowest corrosion rate.

5. Fuzzy Logic method in the surface viewer nitrided zinc metal can be used for introducing or preparing way of corrosion rates of nitrided others metals.

6. Matlab system is easy to use and useful for the beginners. It is also interactive software.

\section{ACKNOWLEDGEMENT}

I would like to thank Ms Yuristi Herlinawati for her assistance in doing this experiment. I also want to thank Ms. Ratmi Herlani and Mr. Mujari (electrochemist), Mr. Yohannes Karmadi (physicist) and others who have already helped me to accomplish this experiment. 


\section{REFERENCE}

1. ......., "Corrosion of Zinc". Knowledge Article from www.Key-toMetals.Com http:/www.key-to-metals.com / Article40.html, Dec. 20 (2006).

2. SUJITNO,TJIPTO et al, "Pengamatan Struktur Kristal dari Lapisan Tipis Nitridasi Besi Hasil Impanasi Ion Nitrogen dengan Mikroskop Elektron", PPPI-PPNY, Batan Yogyakarta, 26 - 27 Mei (1998).

3. I GUSTI KETUT et al; Pengaruh Implantasi Ion TiN Terhadap Ketahanan Korosi Baja Karbon Rendah Pada Media NaCl. Prosding Pertemuan dan Presentai Ilmiah Teknologi Akselerator dan Aplikasinya - P3TM - BATAN, Yogyakarta, 7, 282 - 287, Nov (2005).

4. SANZ. A; "Analog Implementation Fuzzy Controller-Department of Electrical Engeenering and Computer Science University Zarogoza", Spain, idea@cc.unizar.es.www.cps.unizar.es/ $\infty$ te/Publicationes archivos/IE94-FUZ.pdf (Dec 20-2006).

5. ......; "Fuzzy Logic Toolbox For Use With Matlab", User's Guide Books, (May 5-2007) www.matworks.com.

6. YURISTI HERLINAWATI, "Pengaruh Nitridasi Plasma Terhadap Laju Korosi Logam Seng", Tugas Akhir, Sekolah Tinggi Teknologi Nuklir, Yogyakarta (2005).

7. SRI KUSUMADEWI, "Analisis Desain Sitem Fuzzy Meggunakan ToolBox Matlab", Graha Ilmu, Juni (2002).

8. DURAISAMY,V et al; "Comparative Study of Membership Function for Design of Fuzzy Logic Fault Diagnosis system for Single Phase Induction Motor", http://www.acadjournal.com/, Dec. 20 (2006).

9. DE MONCHY ALLAN R et al; Expert Systems for the Analytical Chemistry Chem, 60 No 23 Dec 1, 1355 A - 1361 A (1988).

10. OTTO, M; Fuzzy Sets Application to Analytical Chemistry Anal.Chem., 62, No 14 July 15, 797 A - 802 A (1990). 